\title{
The Relationships among Business Strategies, Organisational Performance and Organisational CULTURE IN THE TOURISM INDUSTRY
}

\author{
Yueh-Hsin Wu \\ Department of Industrial Engineering and Management, Cheng Shiu University, Taiwan
}

Mong-Mei Lin*

Department of Business Administration, National Taichung University of Science and Technology, Taiwan

\begin{abstract}
As societies develop, the tourism industry has become one of the most powerful and largest industries in the global economy. The industrial status and economic function of the tourism industry have increased in the economic development of cities. The tourism industry has helped to drive the city economy, create employment, and facilitate culture and the environment

The tourism industry, as one of the supporting industries for economic development in China, presents diverse services that are not only competitive within the industry, but could also increase national consumption. In addition to the professional service items and quality, the adjustment of business strategies aimed at the changeable environment are considered as key success factors in the tourism industry. This study analyzes the effect of business strategies on organisational performance in the tourism industry. Owners, managers, and employees from the top ten travel agencies in Taiwan were selected as the research subjects and a total of 600 questionnaires were distributed. Within the retrieved 438 surveys, 43 were incomplete and removed to yield a total of 395 valid questionnaires. Within the empirical analyses business strategies appear to have significant positive correlations with job satisfaction, organisational objective and job performance in organisational performance. Moreover, organisational culture presents a partially moderating effect for the relations between business strategies and organisational performance.
\end{abstract}

Key words: tourism industry, business strategies, organisational performance, job satisfaction, organisational culture, organisational goals, job performance, objective strategies, total business strategies, functional strategies

JEL: C120, M100

1

\section{Introduction}

Due to internal as well as external factors, the tourism industry is experiencing numerous operating risks. Operating risks could bring about profit losses and even bankruptcy in the tourism industry, which emphasises the importance of business strategies for managerial activities in the tourism industry. To effectively avoid operating risks, managers in the tourism industry require keen perspicacity to accurately manage the development of the tourism industry and to adjust operational policies for reform.

Because of the fierce competitive and changeable environment of the industry, there are many challenges to the various facets of its operation. To cope with the rapid changes in the external environment, the formulation and timely adjustment of business strategies are essential for its survival. Effective business strategies with accurate directions are regarded as preconditions in the competitive tourism industry. Nevertheless, the same or similar strategies could result in different outcomes and performances owing to the operating competency of role players. Accompanying the business strategies, efficient operating competency should also be ensured to achieve strategic goals and obtain favorable business performance. The formulation of business strategies requires perceptive vision and the efficient allocation of 
restricted resources. Effective application of resources could turn strategies into specific actions to fulfill the strategic goals that are reflected in business performance

This study aims to discuss business strategies and organisational performance in the tourism industry.

\section{2}

\section{Literature review}

\subsection{Business strategies}

Hill and Jones (1998) mention that a business strategy encompasses the specific decisions and actions taken by managers in order to achieve organisational objectives, in which excellent performance is the key objective. Strategy could be defined as specific decisions and actions taken by managers to yield excellent organisational performance. Kenichi (1984) indicate that business strategies are the most efficient way to change a company and to outperform their competitors. The dimensions for business strategies comprise:

1) Key success factor strategy, with which enterprises could effectively invest in resources in key areas for increased revenue performance.

2) Relative advantage strategy, which could be found in the competition differences between a company and its competitors.

3) Active attack strategy, which refers to the change of competition rules when the major competitors present stable bases in the industry. And finally,

4) Strategic degrees of freedom, which was developed with an innovative methodology to avoid direct competition with competitors.

Walker \& Ruekert (1987) consider the dimensions for business strategies as follows:

1) Prospector strategy, to develop new products and markets in the changeable environment.

2) Low cost defender strategy, focusing on potential markets to reduce the costs of present products and to maintain market share. And finally,

3) Differentiated defenders, to consolidate the existing market with unique products and excellent quality and technology.
Noy (1998) classifies the formulation and practice of business strategies into:

1) Objective strategy, which is a permanent strategic objective suitable for many companies.

2) Total business strategy, which considers the marketplace, competitive advantage, leading technology, attitude toward risks, and long-term goals of quantity (e.g., market share) in addition to the goal that total business strategy should be adjusted when the environment and the core competitiveness change, and

3) Functional strategy, to be combined with total business strategies for the strategies formulated by various sectors. This study intends to discuss business strategies based on the dimensions proposed by Noy (1998).

\subsection{Organisational performance}

Walker \& Boyd (1995) point out the possible indices for measuring performance of sales quantity, volume, and change. Organisational performance covers the issues related to the organisational system, process, and performance evaluation, including leadership, decision making, process improvement, logistic support, incentive measurement, innovative learning, and risk management (Chiu, 2008). In general, business performance directly presents the output of products and services, utilisation of human resources, growth of sales, and transaction frequency with customers, while profits or goal achievement are the final test of profit making, employee performance, and organisational effectiveness in an enterprise (Chen, 2010). Campbell (1997) suggests that job satisfaction, organisational objective, and job performance are the measuring indices for organisational performance. This study aims to discuss organisational performance from the above indices, which are further defined below.

1) Job satisfaction: Robbins and Judge (2011) indicate that job satisfaction was due to the general attitude of individuals towards work and that when employees experienced higher job satisfaction they had a more positive attitude towards the work.

2) Organisational objective: Objectives were the standard of work or plans being achieved as well as a correct, specific, and 
reasonable benchmark from internal power.

3) Job performance: Schermerhorn Hunt \& Osborn (2005) regard job performance as the quality and quantity of work of an individual or a team achieving the task at work. Campbell (1991) indicates that job performance is the behavior of an individual completing the expected, formulated, or required role as an organisational member.

\subsection{Organisational culture}

Schein (1996) regards organisational culture as a common viewpoint for enterprise members, which serves as the rule and norm in an organisation. In other words, organisational culture is the common value of enterprise members and the integrated evaluation of a situation, work of art, object, and human, which represents the objectives, goals, and standards of the enterprise. For this reason, organisational culture is considered as the mutual assumption among enterprise members and necessary for coherent, viewpoints and values. Organisational culture is a basic assumption, as well as the findings, invention, and development of an organisation dealing with external adaptation and internal integration. It is also the adoption of effective experience so that new members can present accurate cognition and thoughts when encountering problems. Organisational culture reflects the core values of an organisation and emphasises open communication, devoted challenges, and ethical practices. Mitchell and Yate (2002) considers organisational culture as shared values, beliefs, and comprehension among the members in an organisation. This study applies the dimensions proposed by Frohman (1998) for organisational culture namely:

1) Paternalistic culture: High-level supervisors make decisions, the other staff donot take responsibility, and the junior staff simply execute orders without new ideas, which result in hindered innovation.

2) Individualistic culture: Enterprise members simply do their own businesses without sharing, communication, or mutual assistance. Such a team does not establish regulations for cooperative innovation.
3) Based on the teams' culture: A team presents authority in an organisation; teams are expected to execute the company objective; and a team objective and organisational objective coexists.

4) Culture for innovation at all levels under organisational objective, individual power and concepts were developed through a team.

\subsection{Correlations among business strategies, organisational culture, and organisational performance}

Parthasarthy \& Sethi (2001) investigated the factors of social economy, industrial technology, manufacturing technology, organisational culture, and organisational structure in business strategies of a company. The business performance was restricted in industrial technology, social economy, and the manufacturing technology. It was also affected by the organisational culture, business strategy, and organisational structure of a company. As business strategies could be affected by the environment, the overall environmental change could utilise strategic management theory to become more suitable for practice. The change of strategies could influence the organisational structure and further improve organisational performance. Pan (2011) also discovered distinct performance which resulted from different types of competition strategies and organisational culture. By studying the interactions among the operation environment, business strategies, organisational culture, competitive advantage, and organisational performance, $\mathrm{Yu}$ (2010) found significant effects of operation environment and business strategies on organisational performance. Moreover, with appropriate coordination, operation, environment and business strategies yielded remarkable effects on organisational performance. Apparently, there are significant positive correlations among business strategies, organisational culture, and organisational performance. According to the above studies, industrial environment and competitive status are regarded as the direct effects on organisational performance, followed by business strategies and organisational structure. Enterprises could therefore change the industrial environment and competitive status with strategies and 
structure. In this case, the effects of business strategies on organisational performance became critical.

Based on the above points, the following hypotheses were proposed in this study:

H1: In organisational performance business strategies present significant positive correlations with job satisfaction.

$\mathrm{H} 2$ : In organisational performance business strategies exhibit significant positive correlations with organisational objective.

H3: In organisational performance business strategies reveal notable positive correlations with job performance

\subsection{Organisational culture}

To evaluate the above research on business strategies and organisational performance, the following additional hypotheses were further proposed in this study.

H4: The correlations between business strategies and organisational performance show significant differences in a paternalistic culture.
H5: The correlations between business strategies and organisational performance present significant differences in an individualistic culture.

H6: The correlations between business strategies and organisational performance show significant differences based on the teams' culture.

H7: There are notable differences in the correlations between business strategies and organisational performance in a culture for innovation at all levels.

\section{3}

\section{Research method}

\subsection{Research framework}

Based on domestic and international research on business strategies and organisational performance, the research framework was proposed to discuss the correlations between business strategies and organisational performance as in Figure 1.

Figure 1

Research framework

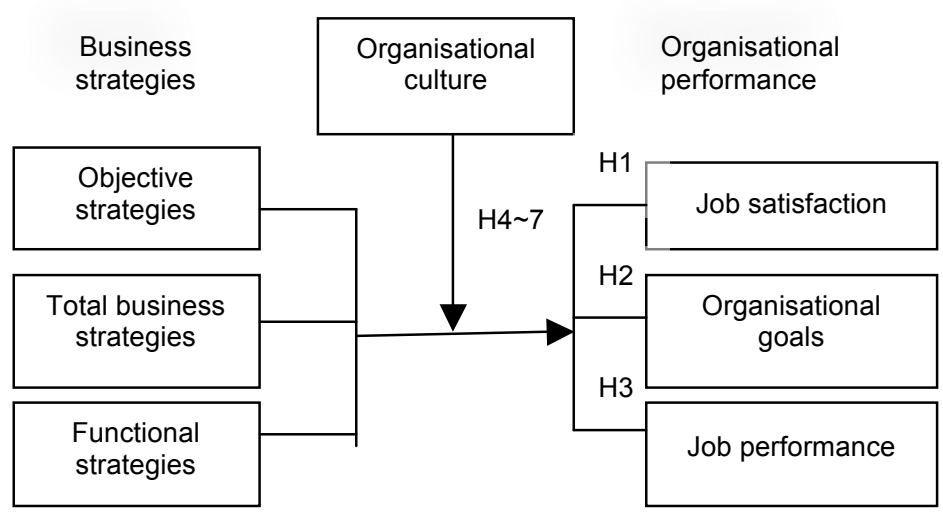

\subsection{Research subject and sampling}

Using random sampling, questionnaires were distributed and collected onsite. The owners, managers, and employees in the top ten travel agencies announced by the Consumer's Foundation Taichung were selected where the following seven items were evaluated, including:

1) Pre-departure service;

2) Leasing service;
3) Local tour guide service;

4) Expenses;

5) Schedule planning;

6) Accommodation; and

7) Dining. The degree of emphasis on the evaluated items was analysed for the weighted average.

A total of 600 questionnaires were distributed in South East Travel, Phoenix Tours, Hong 
Thai Travel, Lion Travel, Beneficial Travel, Life Tour, Cola Tour, Hi-Lite Tours, Skylark Travel, and Ming Tai. 43 incomplete questionnaires were removed from the collected 438 surveys, yielding a total of 395 retrieved and valid copies. Each retrieved questionnaire was regarded as a valid sample of owners, managers, and employees in the tourism industry. It corresponded with the purpose of this study regarding the effect of the business strategies on organisational performance in the tourism industry.

\section{4}

\section{Analysis and discussion}

\subsection{Factor analysis of business strategies}

The business strategies scale was based on the dimensions and questionnaire proposed by Noy (1998). With factor analysis, the Cronbach's $\alpha$ reliability of each dimension appears as 0.88 (objective strategies), 0.85 (total business strategies), and 0.90 (functional strategies). With principle component analysis and oblique rotation, the variance taken was 83.381 per cent.

\subsection{Correlation analysis of business strategies and job satisfaction in organisational performance}

With a multiple regression analysis to test $\mathrm{H} 1$, the results showed significant effects of objective strategies $(\beta=0.173, p<0.05)$ and functional strategies $(\beta=0.169, \mathrm{p}<0.05)$ on job satisfaction agreeing with $\mathrm{H} 1$.

\subsection{Correlation analysis of business strategies and organisational objective in organisational performance}

With multiple regression analysis to test $\mathrm{H} 2$, the results presented significant effects of objective strategies $(\beta=0.212, p<0.01)$, total business strategies $(\beta=0.206, p<0.01)$, and functional strategies $(\beta=0.187, p<0.05)$ on organisational objective agreeing with $\mathrm{H} 2$.

\subsection{Correlation analysis of business strategies and job performance in organisational performance}

With multiple regression analysis to test $\mathrm{H} 3$, the results revealed notable effects of objective strategies $(\beta=0.185, p<0.05)$, total business strategies $(\beta=0.224, p<0.01)$, and functional strategies $(\beta=0.217, p<0.01)$ on job performance that proving H3. This is shown in Table 1.

\subsection{Moderating effects of organisational culture}

\subsubsection{Effects of a paternalistic culture on the relations between business strategies and organisational performance}

With analysis of variance, paternalistic culture displayed significant differences in the relations between total business strategies and job satisfaction in functional strategies, between objective strategies, functional strategies and organisational objective, and between objective strategies, functional strategies and job performance that partially agrees with $\mathrm{H} 4$. This is shown in Table 2.

Table 1

Multiple regression analysis of business strategies and job performance in organisational performance

\begin{tabular}{|c|c|c|c|}
\hline \multirow[b]{2}{*}{ Independent variable } & \multicolumn{3}{|c|}{ Organisational performance (dependent variable) } \\
\hline & $\begin{array}{c}\text { Job } \\
\text { satisfaction }\end{array}$ & $\begin{array}{c}\text { Organisational } \\
\text { objective }\end{array}$ & $\begin{array}{c}\text { Job } \\
\text { performance }\end{array}$ \\
\hline \multicolumn{4}{|l|}{ Business strategies } \\
\hline Objective strategies & $0.173^{*}$ & $0.212^{* *}$ & $0.185^{*}$ \\
\hline Total business strategies & 0.102 & $0.206^{* *}$ & $0.224^{* *}$ \\
\hline Functional strategies & $0.169^{*}$ & $0.187^{*}$ & $0.217^{\star *}$ \\
\hline $\mathrm{F}$ & 21.786 & 27.914 & 31.844 \\
\hline Significance & $0.000^{* * *}$ & $0.000^{* * *}$ & $0.000^{* * *}$ \\
\hline $\mathrm{R}^{2}$ & 0.175 & 0.217 & 0.304 \\
\hline Regulated $\mathrm{R}^{2}$ & 0.206 & 0.243 & 0.336 \\
\hline
\end{tabular}

Note: * stands for $p<0.05,{ }^{* *}$ for $p<0.01$ 
Table 2

Effects of paternalistic culture on the relations between business strategies and organisational performance

\begin{tabular}{|c|c|c|c|}
\hline Business strategies & Job satisfaction & Organisational objective & Job performance \\
\hline Objective strategies & Not significant & Significant & Significant \\
\hline Total business strategies & Significant & Not significant & Not significant \\
\hline Functional strategies & Significant & Significant & Significant \\
\hline \multicolumn{2}{|r|}{ Hypothesis test } & H4 partially agreed \\
\hline
\end{tabular}

\subsubsection{Effects of individualistic culture on the relations between business strategies and organisational performance}

With analysis of variance, individualistic culture exhibited notable differences in the relations between objective strategies, functional strategies and job satisfaction, between total business strategies, functional strategies and organisational objective, and between objective strategies, total business strategies and job performance that also partially agrees with H5. This is reflected in Table 3 .

Table 3

Effects of individualistic culture on the relations between business strategies and organisational performance

\begin{tabular}{|c|c|c|c|}
\hline Business strategies & Job satisfaction & Organisational objective & Job erformance \\
\hline Objective strategies & Significant & Not significant & Significant \\
\hline Total Business strategies & Not significant & Significant & Significant \\
\hline Functional strategies & Significant & Significant & Not significant \\
\hline \multicolumn{2}{|c|}{ Hypothesis test } & H5 partially agreed \\
\hline
\end{tabular}

\subsubsection{Effects on the relations between} business strategies and organisational performance, based on the team's culture

With analysis of variance, considering the team's culture, there appeared to be significant differences in the relations between objective strategies and job satisfaction. The relations between total business strategies, functional strategies and organisational objective, and between total business strategies, functional strategies and job performance also partially agree with H6, as shown in Table 4.

Table 4

Effects based on the team's culture and on the relations between business strategies and organisational performance

\begin{tabular}{|c|c|c|c|}
\hline Business strategies & Job atisfaction & Organisational objective & Job performance \\
\hline Objective strategies & Significant & Not significant & Not significant \\
\hline Total business strategies & Not significant & Significant & Significant \\
\hline Functional strategies & Not significant & Significant & Significant \\
\hline Hypothesis test & & $\mathrm{H} 6$ partially agreed \\
\hline
\end{tabular}

\subsubsection{Effects of culture for innovation at all levels on the relations between business strategies and organisational performance}

With analysis of variance, there appear to appear to be significant differences in Culture for innovation on all levels differences of the relations between objective strategies, functional strategies and job satisfaction and between total business strategies and organisational objective, as well as between objective strategies, functional strategies and job performance. This partially agrees with H7as shown in Table 5. 
Table 5

Effects of culture for innovation at all levels on the relations between business strategies and organisational performance

\begin{tabular}{|c|c|c|c|}
\hline Business strategies & Job satisfaction & Organisational objective & Job performance \\
\hline Objective strategies & Significant & Not significant & Significant \\
\hline Total business strategies & Not significant & Significant & Not significant \\
\hline Functional strategies & Significant & Not significant & Significant \\
\hline Hypothesis test & & H7 partially agreed & \\
\hline
\end{tabular}

5

\section{Conclusions and suggestions}

To summarise the data analyses and research conclusions, suggestions for the practical application of business strategies are proposed below.

1) Driver business strategies. The tourism industry represents a very comprehensive sector for selling travel products. The production and management of travel products are involved in several industries and sectors, such as transportation, architecture, culture, hygiene, and public security. The tourism industry could therefore connect with various businesses to expand diverse operations, such as establishing hotels, automobile companies, recreation areas, and markets. Such businesses would provide additional convenience for tourists, and the tourism industry could make higher profits from diverse operations.

2) Establishment of an information system for the tourism industry. From continuous up to date information, the tourism industry could develop products and expand its market. Information is important to all the various industries in that whoever masters the information would control the wealth. For international or domestic tours, travel agencies should establish branches in major touring spots in the world to be at the forefront of demand for products and market information. With skilled personnel in the tourism industry to collect, organise, and analyse such information, they could become the indicators for product development, and the tourism industry which could continuously develop products and expand the market.

3) Enhancement of resource utilisation. Through its communication with the broad public the tourism industry can benefit by attracting businesses and investment. The tourism industry attracts hundreds of thousands of domestic and international tourists every year, and the travel consumption would determine the level and status of tourists. By tailoring management and service standards 1 to the needs of tourists would encourage them to invest and cooperate in the industry. The industry could attract businesses and investment to develop diverse operations to expand on many levels in many areas.

\section{Acknowledgement}

The authors are grateful to the valuable comments made by the reviewers.

*CORRESPONDING AUTHOR CONTACT

Mong-Mei Lin,mmlin@nutc.edu.tw

\section{References}

CAMPBELL, J.P. 1991. Handbook of industrial and organizational psychology ( $2^{\text {nd }}$ ed.) New York, NY: Consulting Psychologists Press.

CAMPELL, J.P. 1997. On the nature of organizational effectiveness: New perspective on organization. San Francisco, CA: Jossey-Bass.

CHEN, SHUI-CHU. 2010. Organizational behaviors-Theoretical application and industrial development. Journal of Administration and Policy, 45:1-34. 
CHIU, CHI-HE. 2008. Leadership strategies and organizational performance management, Journal of Public Administration, 26:37-69.

FROHMAN, A.L. 1998. Building a culture for innovation, Research Technology Management, 41:9-12.

HILL, C.W.H. \& JONES, G.R. 1998. Strategic management theory: An integrated approach $\left(4^{\text {th }} \mathrm{ed}.\right)$ Houghton Mifflin.

KENICHI OHMAE. 1984. The mind of strategist: The art of Japanese business, Japan, President Inc MITCHELL, M.A. \& YATE, D. 2002. How to use your organizational culture as a competitive tool. Nonprofit World, Madison, 20(2):33-34.

NOY, E. 1998. Total business strategy- The missing link, Long Range Planning, 31(6):927-932.

PAN, CHIEN-CHIH. 2011. The relations between leadership style and business performance of business groups. Journal of Management, 14(2):277-302.

PARTHASARTHY, R. \& SETHI, S.P. 2001. The impact of flexible automation on business strategy and organizational structure, Academy of Management Review, 86-111.

ROBBINS, S.P. \& JUDGE, T.A. 2011. Organizational behavior $\left(14^{\text {th }}\right.$ ed.) Upper Saddle River, NJ: Pearson Education International, Inc.

SCHEIN, E.H. 1996. Organizational culture and leader (2 ${ }^{\text {nd }}$ ed.) San Francisco: Jossey-Bass Publishers. SCHERMERHORN, J.R., HUNT, J.M. \& OSBORN, R.N. 2005. Managing organizational behavior $\left(9^{\text {th }}\right.$ ed.) New York, NY: John Wiley \& Sons, Inc.

WALKER, O.C. \& BOYD, H.W. 1995. Marketing strategy: planning and implementation ( $2^{\text {nd }}$ ed.) Irwin, Chicago.

WALKER, O.C. \& RUEKERT, R.W. 1987. Marketing's role in the implementation of business strategies: a critical review and conceptual framework. Journal of Marketing:51-75.

YU, YUNG-SHENG, 2010. A study on operation environment and strategy application of Chinese, American, and Japanese enterprises in Taiwan and China. Sun Yat-Sen Management Review, 3(4):106-131. 